علاقة بعض المتغيرات الكينماتيكية لمهارة التصويب من الققز عالباً بدقة التصويب اتب في كرة البيد

أ.د. ضياء قاسم الخياط أ.م.د. عمار علي إد. محمد خليل محمد

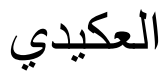
احسان

جامعة الموصل / كلية التربية الرياضية

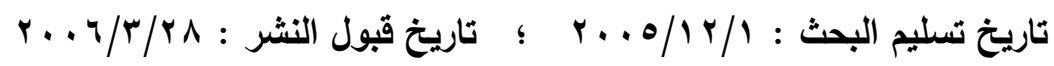

ملخص البحث: : ملاف :

تهذف هذه الدراسة الى :

التعرف على قيم أهم المتغيرات البايوميكانيكية لمهارة التصويب من الققز عالياً في كرة اليد

وكذللك التعرف على العلاقة بين قيم هذه المتغيرات وكذللك مع دقة التصويب في كرة اليد.

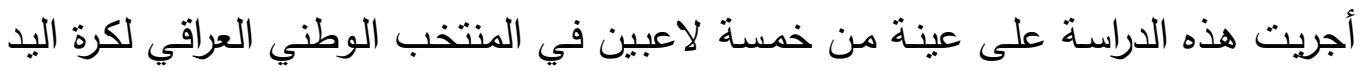

والذين يجيدون التصويب من خارج منطقة الـ 9 منر .

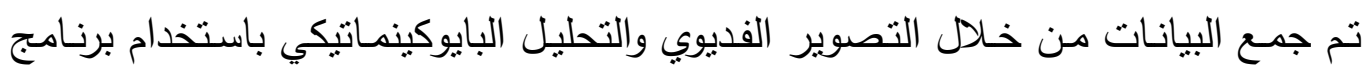

وبرنامج (Adob Photoshop)

وقد أسفرت النتائج عن:

ا ـ وجود اختلاف في قيم بعض المتغيرات البايومينكاتيكية للأداء الحركي لمهارة التصويب من

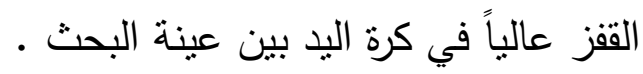

r. تؤثز الزيادة في زمن خطوة الاقتراب الأخيرة سلبياً على سرعة الخطوة ومن ثم تؤثر في سرعة

حركة الرمي.

r. العلاقة بين المتغيرات البايوكينماتيكية كانت أكثرها ضعيفة مما بعكس ضعف اداء اللاعبين.

ويوصي الباحثون :

ا ـ ضرورة إعطاء معلومات اللاعبين عن الحركات المثالية للتصويب وذلك من اجل التقليل من

الأخطاء وبذللك تعمل على تقريب وتثابه الأداء.

r. ضرورة أعطاء أولوية في التصويب على الأداء الفني وتحسين أداء الجسم. 


\section{The relationship between some biokinematics variables of high-jump shooting skill with the accuracy in handball}

\section{Dr. Dia K. Al-Kaeat Dr. Amar Ali Ehsan Dr. Mohammed K. Al-U'kaelly}

\section{University of Mousl - College of Sport Education}

\section{Abstract:}

This study aims at identifying for more important valves of biokinematics variables of high- jump shooting skill in handball . it also aims at identify the venation shop between among these variables and with the accuracy the sample of the study was five players which play in the Iraqi national team of handball who have agood abolition in shooting of from out side of the nine meter area the data collected though tow video cameras biok (adobe photo shop ) programs and (AutoCAD ) programs analize the of values of body joints angels biockenamheally the study revealed the following results .

1. there were differences in the valves at the biogenetic variables at high-jump shooting skill .

2. the increase in the time at the last approaching step influenced the negatively the step speed .

3. the biokenmatic variables relation ship were weak which mean poor performance.

the recommendations were as the following .

1. priority should be the player information about ideal movements it is to give for improving the performance

2. the technical performances to flyers at this skill in training 


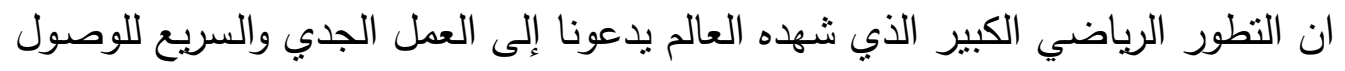

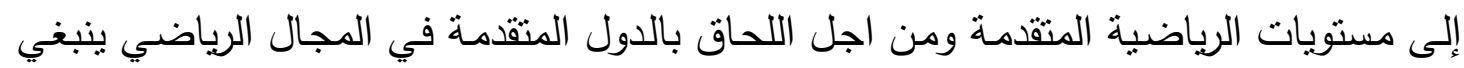

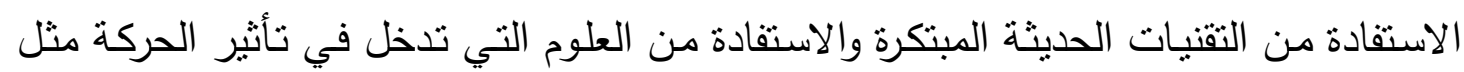

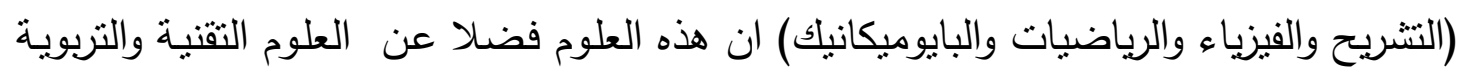

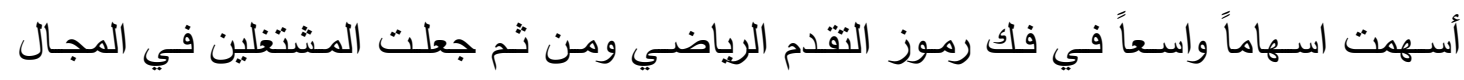
الرياضي يتفننون في إظهار الحركات الرياضية بشكل يكاد لاتصدقه العين من الجودة والإنارة

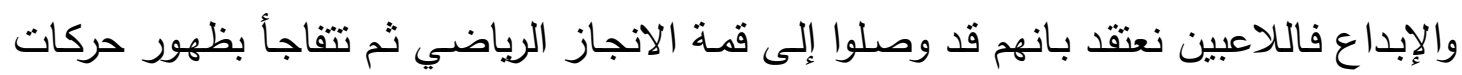
أخرى أكثر جمالاً.

ان هذا الإبداع ليس بنتيجة جهود جاءت من فراغ وإنما نتيجة دراسة علمية مقننة للعلوم

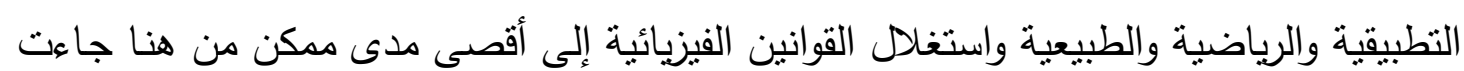
الفائدة من المنشغلين في المجال الرياضي إلى الإمام بهذه العلوم الكثيرة.

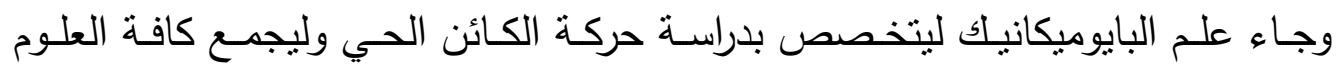
الأخرى وجعلها تتطوي تحت لواءه ليقود هذا التقدم في المجـال الرياضـي وليتعدد مصنادره

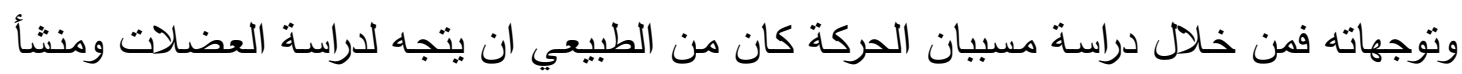

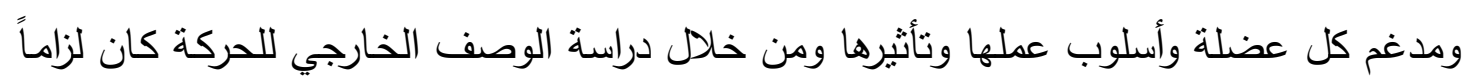
عليه ان يدرس مفاصل الجسم وطبيعة عمل كل مفصل من خلال ارتباط كل عظم مع الاخر

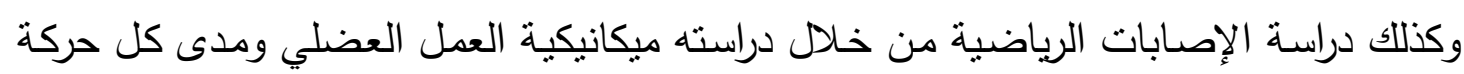
للمفاصل.

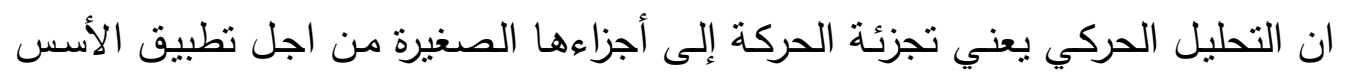

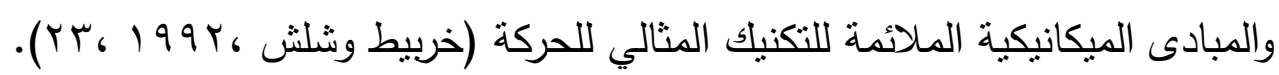

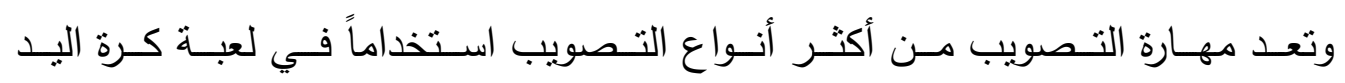
(اسماعيل ، 1997 ،00) من هنا تتجلى أهمية أجراء دراسـة حول التصويب البعيد من القفز

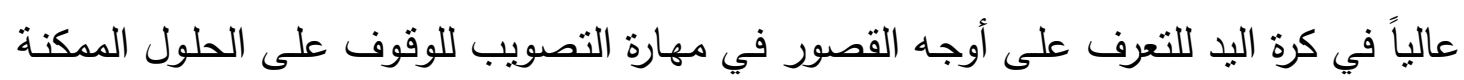
التي يمكن ان تطور هذه المهارة عند لاعبي المنتخب الوطني العراقي لكرة اليد.

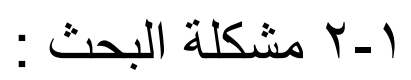

ان النطور التقني الذي شهده العلم في كثثر من المجالات المختلفة يجعلنا نفكر في

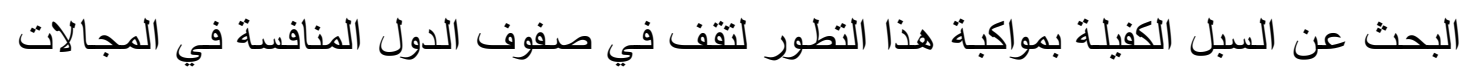


الرياضية كافة وعدم الاكتفاء فقط بالمشاركة في الدورات الرياضية من دون التفكير في الحصول

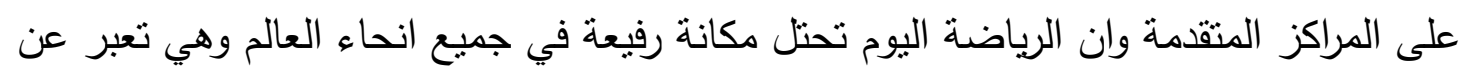
مدى تطور وتقدم الثعوب.

وتدخل لعبة كرة اليد ضمن الألعاب التي شهدت تطوراً سريعاً من الناحيتين التكتيكية

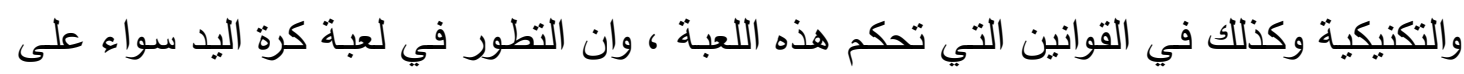

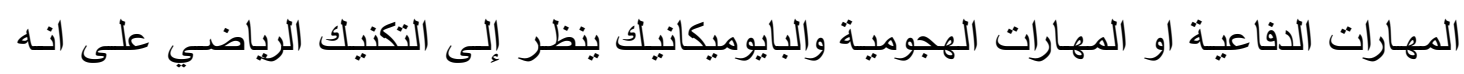

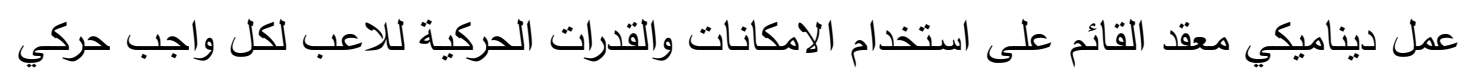

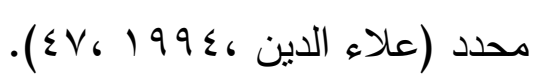
ومن اجل تطوير لعبة كرة اليد كان لابد من التعرف على المشاكل التي تواجه اللاعبين

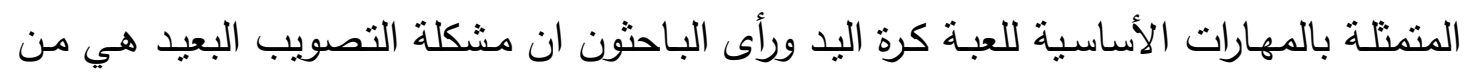

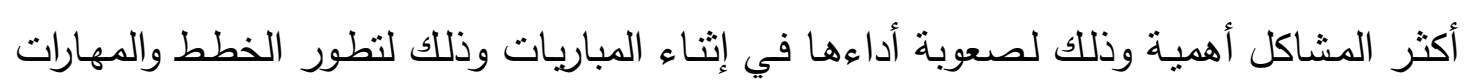

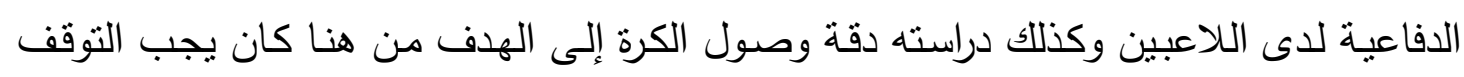

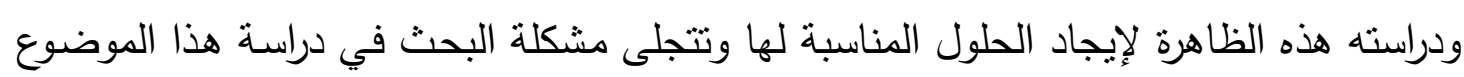
والتعرف على بعض المتغيرات البايوكينماتيكية المؤثرة على التصويب ودقته من اجل التوصل

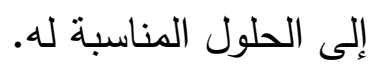

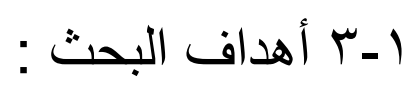

ا ـ التعرف على قيم بعض المتغيرات البايوكينماتيكية لمهارة التصويب من القفز عالياً في كرة

r. التعرف على العلاقة بين قيم المتغيرات البايوكينماتيكية لمهارة التصويب من الققز عالياً ودقة

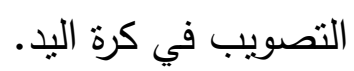

$$
\text { : (المجال }
$$

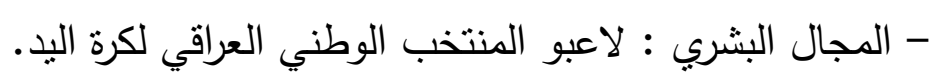

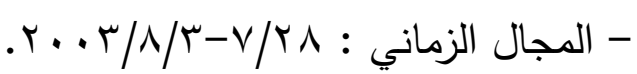

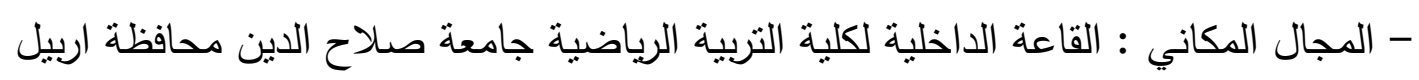




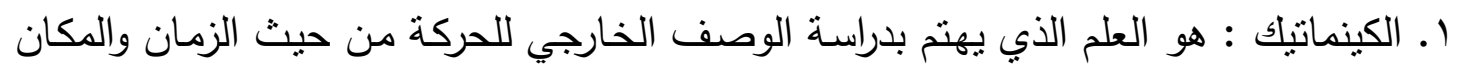

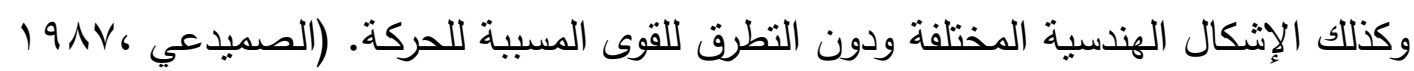

r. الدقة : هي قابلية التواقف الحركي التي تساعد على الحل السريع للواجبات الحركية وبصورة

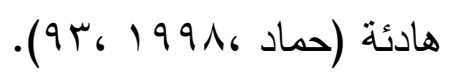

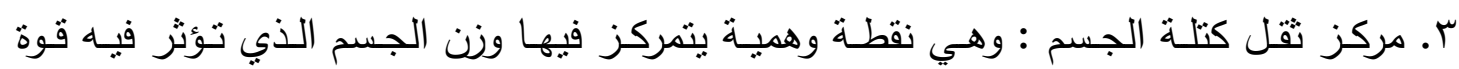

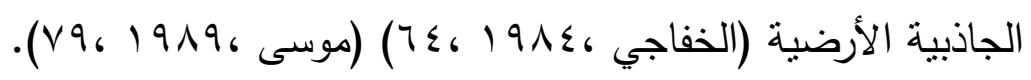

$$
\begin{aligned}
& \text { Y - الدر اسات النظرية و الدر اسات السابقة }
\end{aligned}
$$

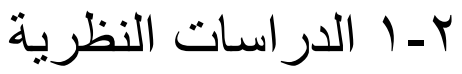

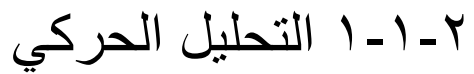

وهو احد الطرائق الاساسية لعلم البايوميكانيك وان التحليل يعتبر طريقة لمعرفة سلوك ومسار حركة الإنسان عن طريق تجزئة هذه الحركة إلى أجزاء حتى يتسنى دراستها ومعرفة لئنة العلاقة بين متغيرات الحركة والمسار الذي سلكته ومن ثم تحويلها إلى أرقام ودرجات (خربيط

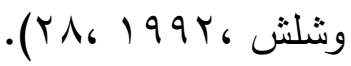

ان التحليل في مجالات المعرفة الانسانية هو الوسيلة المنطقية التي يجري من خلالها

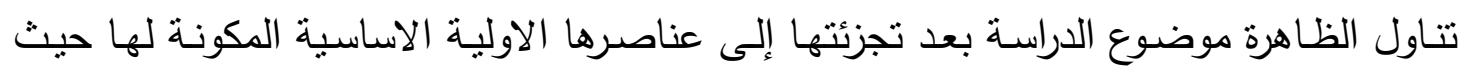
تبحث هذه العناصر كل على حدة وينبغي وضع في الاعتبار ان تجزئة الظاهرة هي ليست هدفاً بحد ذاته وانما وسيلة للوصول إلى الادراك الثمولي للظاهرة ككل.

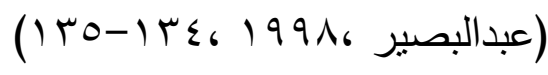

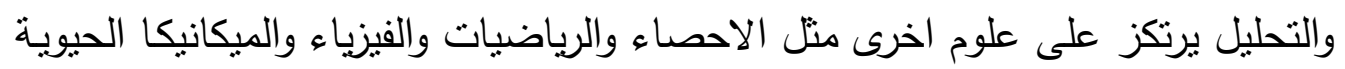

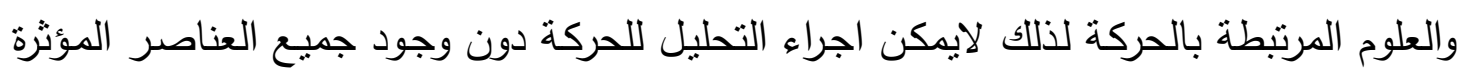

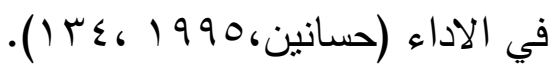

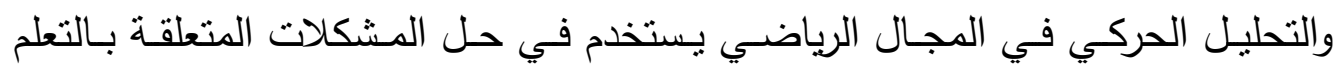

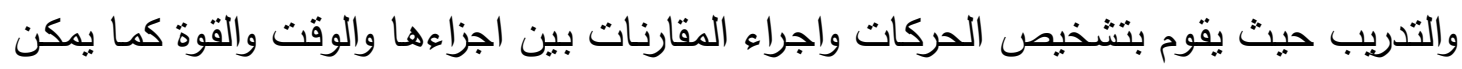

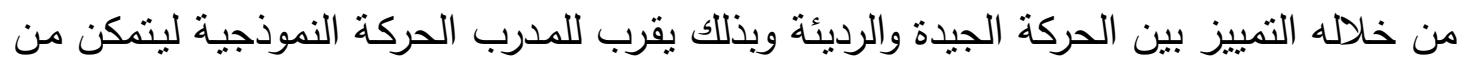
اختبار وسائل وطرائق التدريب الخاصة لإيصالها إلى المتعلم من اجل تجنب الاخطاء الحركية

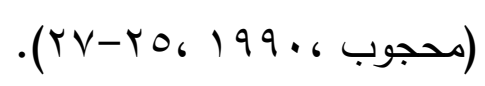

وهذا يعني تقويم العملية التدريبية بقياسها موضوعياً من خلال استخدام الاجهزة العلمية. 
وتهـتم هـذه الطريقـة بتوضيح ووصـف انـواع الحركـات المختلفـة عـن طريـق اسـتخدام المدلولات الخاصـة بالسرعة والتعجيل الذي وضـع على أسـاس قياسـات المسافة والزمن ونستخدم في تحقيـق ذلك وسـائل منها: (التصوير الدائري ، التصوير السينمائي، التصوير بالفيديو)

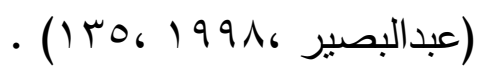

\section{r - ا - ب التصويب في كرة البد :}

يعد التصويب من اهم المهارات الأساسية في كرة اليد ويمكن اعتبار الهدف الأساسي في كرة اليد هو الوصسول إلى عمليـة التصويب والمهارات تصبح عديمـة الفائدة اذا لـم تتتهي بالتصويب (عربي ،199، 19 ، ع). والتصويب أداء توافقي حركي يتصف بالقوة والسرعة ودقة ردي الكرة نحو الهدف وهو

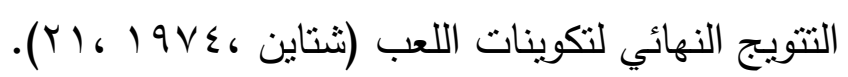
ان هدف المهارات الهجومية لفريق كرة اليد هو تسجيل اكبر عدد من الاهداف لتحقيق

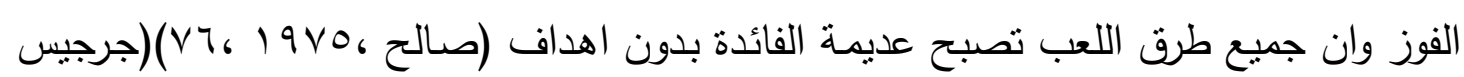
.(^. ، 19人r。

ان التصويب هو جهداً يبدأ بحسارس المرمى مـروراً بـاللاعبين وانتهاء باللاعب الذي سيصوب في نهايـة الخطـة الهجوميـة ويجب ان يسبق عمليـة التصويب تحركات منسقة مـن اللاعبين ومخطط لها مسبقاً حتى لا يكون التصويب عشوائي وبلا فائدة.

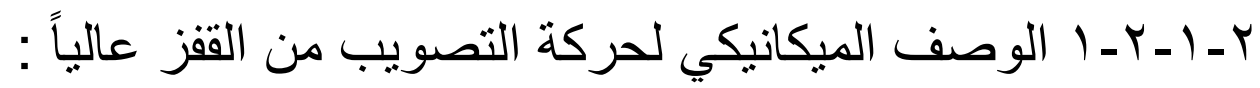
ان جسم الإنسان من ناحية ميكانيكية هو مجموعة من المفاصل التي تربط العظام التي بدورها تكون العتلات وتمثل العضلات في الجسم دور المحرك الذي يساهم بأداء الحركة فعند الاقتراب أثناء التصويب تقدم الرجل الناهضة إلى الإمام حيث يضع قدم الرجل الناهضة كاملة على الأرض وتكون الرجل الأخرى مثبته إمـام الجسم وللخارج قليلاً وبزاويـة قائمسة في مفصل الركبة ويكون مركز تقل الجسم عمودياً على قدم الارتقاء والجذع مائلاً إلى الإمام قليلاً والذراعان تكونان حاملتان الكرة إمام الجسم ثم يبدأ مد الساق الناهضة إلى الأعلى فتأخذ شكل الامتداد

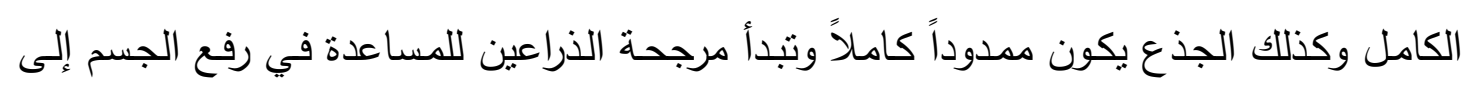

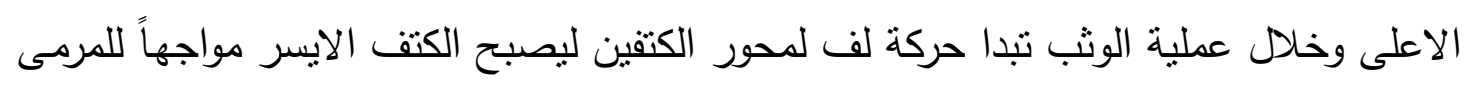

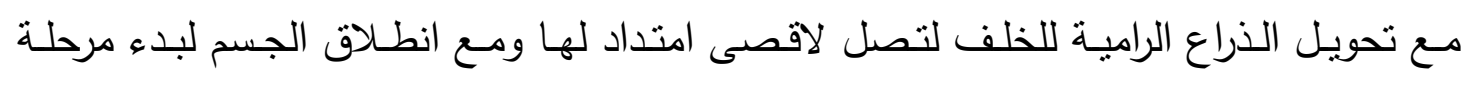
الطيران التي يتم من خلالها الاحتفاظ بوضع الراس والنظر تجاه المرمى يتم مد الجزء العلوي من 
الجسم وتحريك الرجل الحرة المثنية للخارج مما يساعد في المحافظة على توازن الجسم وبدء

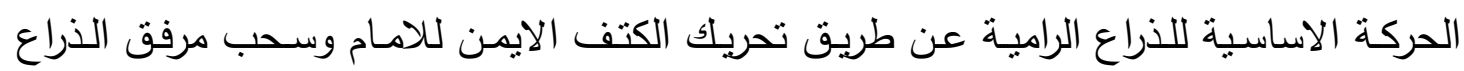

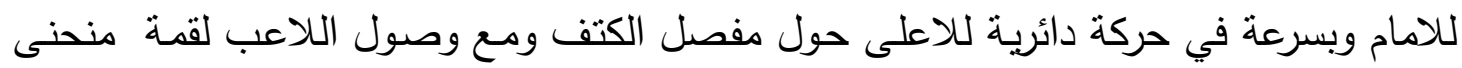

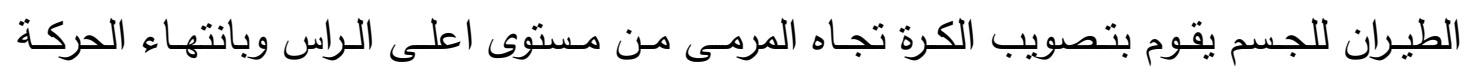

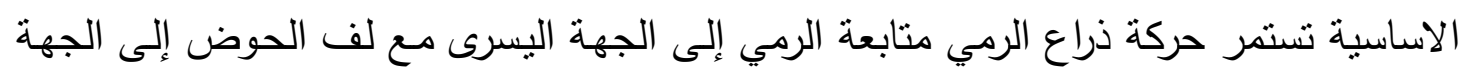

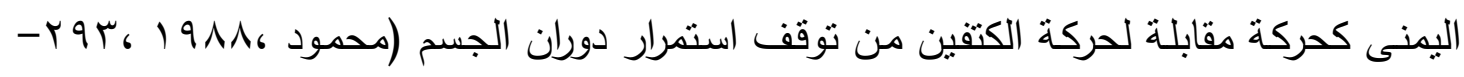

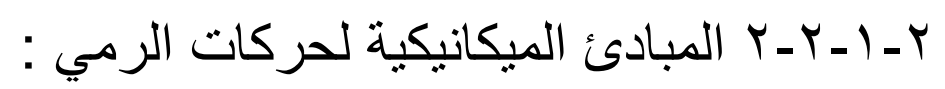

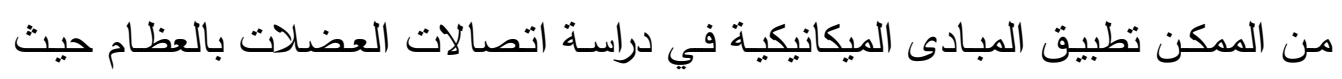

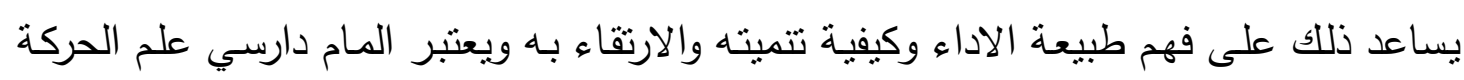
بمفهوم الاجزاء الميكانيكية كنظم تستخدم في انتاج الحركة بمواصفاتها المختلفة على درجة كبيرة

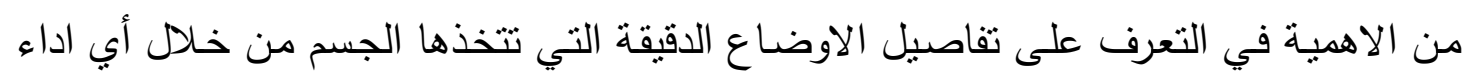

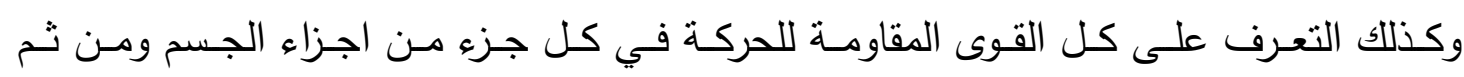
المحصلات النهائية للحركة وللميكانيكا بصورة عامـة اصولها التي تحكم أي تصميم او نظسام

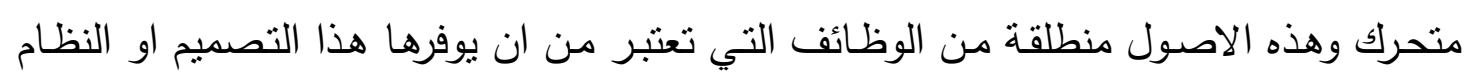
وفي مجال الحركة يمكن ان توجز اهم هذه الوظائف: - بذل مقدار من القوة للتغلب او معادلة مقدار كبير من المقاومة. - الحصول على مدى حركي واسع يتميز بالسرعة.

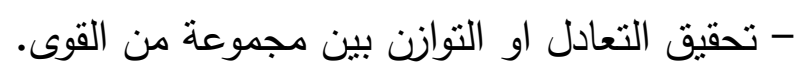

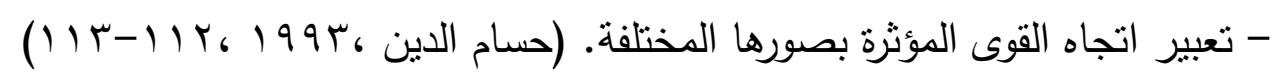

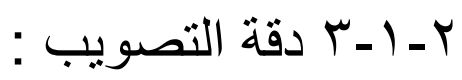
وهي قابلية اللاعب على اصابة المرمى عن طريق توجيه الحركات الارادية للعضلات

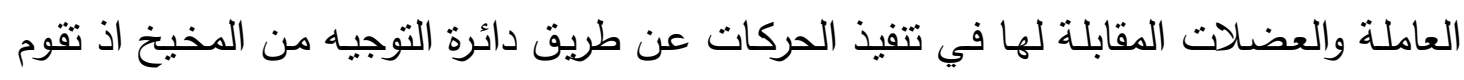

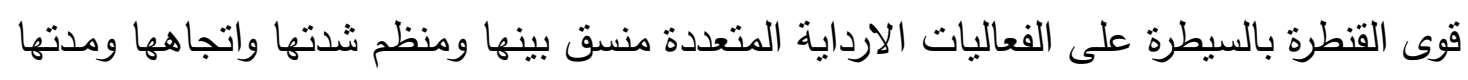
اعتماداً على الذاكرة الحركية الناتجة من جراء التنريب والتكرار.

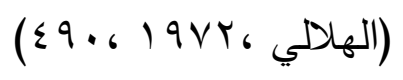

ودقة الحركات ناتجة من توجيه الحركات الارداية التي يقوم بها اللاعب نحو هدف معين

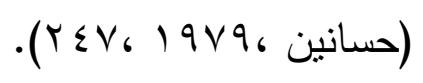


وقابلية التوجيه هي احدى قابليات الدقة الحركية وهي تعبير جامع لقابلية الترابط الحركي اذ يمنلك الرياضي هذه الصفة عندما يؤدي حركات ذات درجة من الصعوبة كالتصويب والقفز

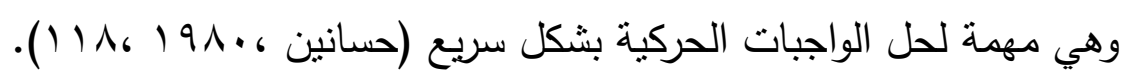

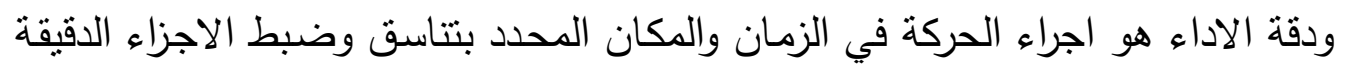

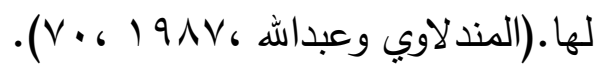

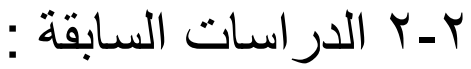

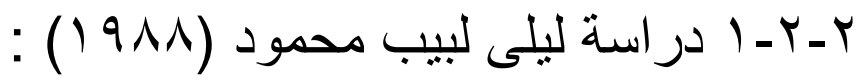

"تحليل بعض المتغيرات الميكانيكية لمهارة التصويب بالوثب عالياً في كرة اليد"

المنهج المستخدم : استخدم المنهج الوصفي واستخدمت الباحثة التصوير الفديوي. العينة : (0) لاعبات من المنتخب المصري لكرة اليد. النتائج : - عدم وجود اختلافات في الخصائص الميكانيكية بين الاداء الحركي لمهارة التصويب من

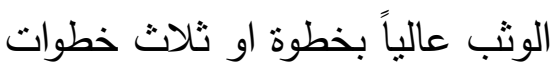

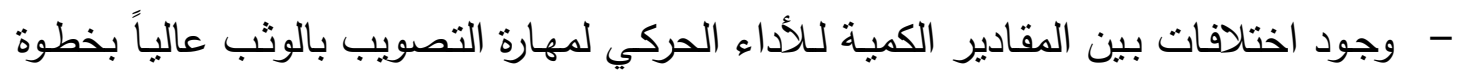

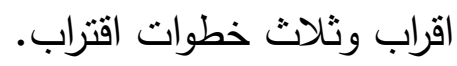

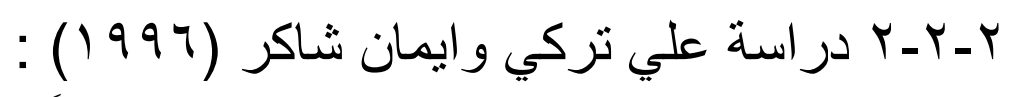

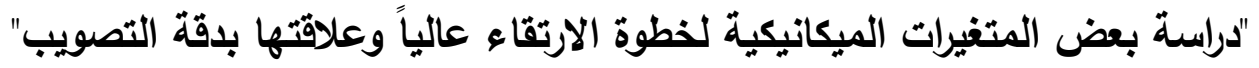

$$
\text { هدفت الاراسة إلى: }
$$

دراسة العلاقة بين بعض المتغيرات الميكانيكية لخطوة الارتقاء وعلاقتها بدقة التصويب. المنهج المستخدم : استخدم المنهج الوصفي واستخدم الباحثان التصوير السينمائي. العينة : ( • () لاعبين من المنتخب الوطني العراقي بكرة اليد.

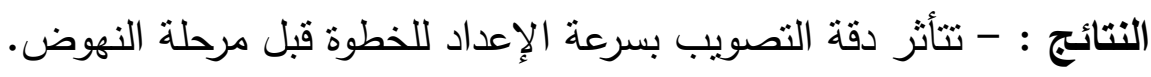
- لاتتاثر دقة التصويب بزاوية انطلاق الكرة. 


$$
\text { rـ إ إجراءات البحث: }
$$

تم استخدام المنهج ألوصفي بطريقة المسح لملاءمته وطبيعة البحث.

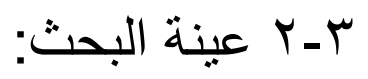

تألفت عينة البحث من (0) لاعبين من اعضاء المنتخب الوطني العراقي فئة المتقدمين

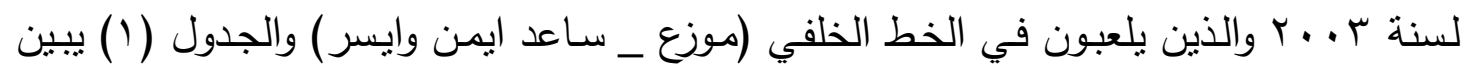

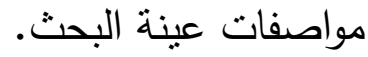

\begin{tabular}{|c|c|c|c|c|c|c|}
\hline الجذع & طول الرجل & (سم) & (كف) & النادي & اسم اللاعب & $ت$ \\
\hline Ar & 91 & int & vo & ديالى & رعد علي & 1 \\
\hline 19 & 94 & INY & v. & الكرخ & احمد خميس & r \\
\hline 10 & $1 \cdot V$ & 194 & $9 \varepsilon$ & الكرخ الكرخ & نعمان منذر & $r$ \\
\hline$V_{7}$ & 91 & INT & Nr & 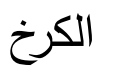 & إبراهيم فنجر & $\varepsilon$ \\
\hline VY & 90 & ivi & vr & الكرخ ال & قصي عبداللطيف & 0 \\
\hline$\vee \wedge, \wedge$ & $9 \wedge, \mathrm{r}$ & IAr,r & vq & & الوسط الحسابي & 7 \\
\hline $0, .7$ & $0, r_{0}$ & $V, \Sigma\rceil$ & 9,74 & & الاتحراف المعياري & v \\
\hline
\end{tabular}

\section{(1) الجدول (1)}

يبين المعالم الإحصائية لكتلة وأطوال اللاعبين وطول أجزاء الجسم(*)

تم استخدام الوسائل آلاتية لجمع البيانات

ب - ب الاستبيان

ع - اختبار دقة التصويب من الققز عالياً في كرة اليد
1- الماحظة العلمية التقنية.

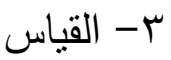

ب- ب- الملاحظة العلمية التقنية

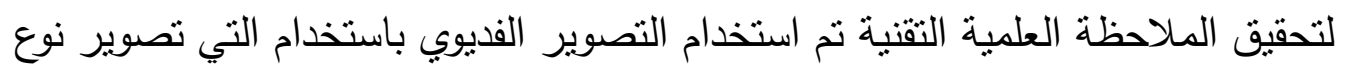
(Y, Yo (Sony Digital) 
اللاعب وبارتفـاع (V • , ( ) م عـن سطح الارض للتعرف على قيم المتغيـرات البايوميكانيكيـة

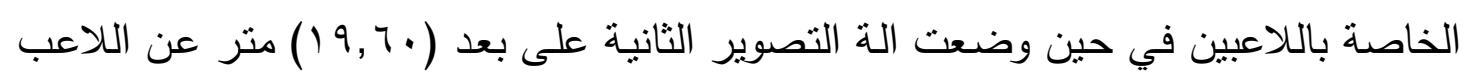

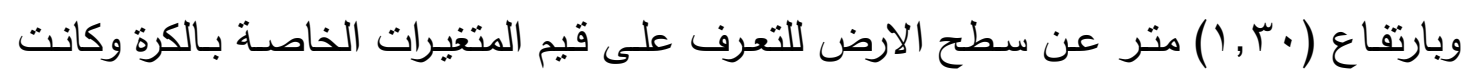

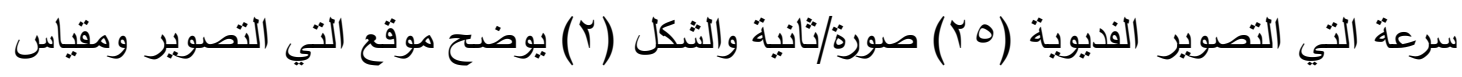

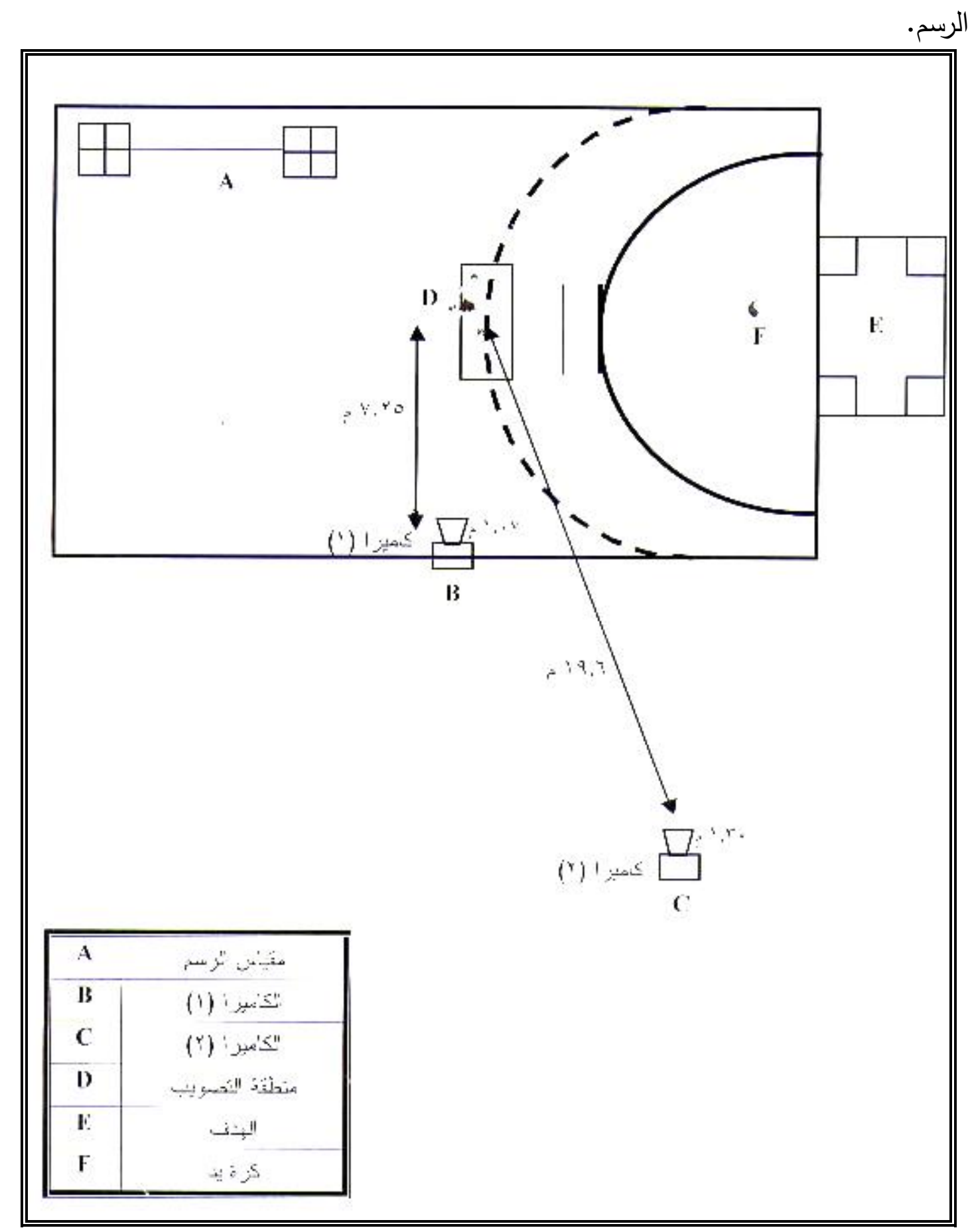

(1) الشكل (1) (1)

يوضح موقع التي التصوير ومقياس الرسم 
عند تقييم اداة القياس فالصدق والثبات والموضوعية يجب ان تؤخذ في الاعتبار كأسس

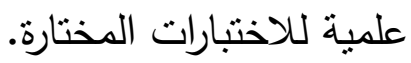

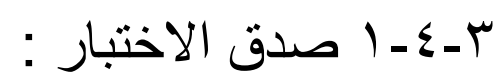

تعد درجـة الصدق العامل الاكثر اهميـة لمكان جودة الاختبـارات والقيـاس فالاختبـار

الصادق هو الذي يقيس بدقة كافية الظاهرة التي صمم لقياسها.

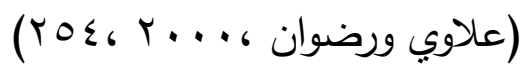

وقد استخدم الباحثون صدق المحتوى (المضمون) في تحديد صدق الاختبار من خلاد وله

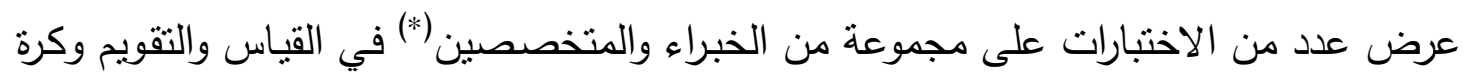

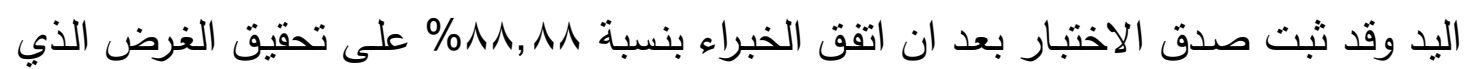
وضع من اجله.

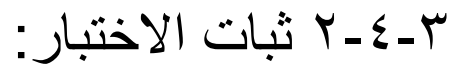

تم إيجاد معامل الثبات عن طريق اعادة الاختبار اذ ان الاختبار الثابت هو الذي يعطي

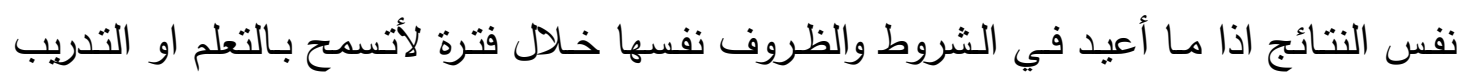

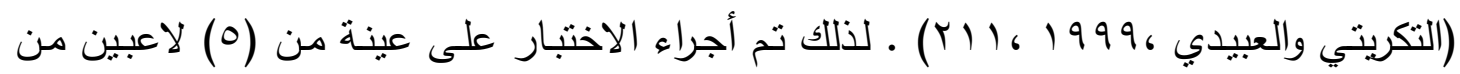

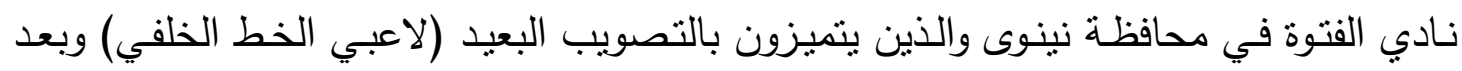

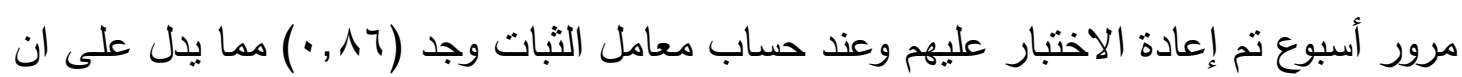
الاختبار يتتنع بثبات عالي.

\begin{tabular}{|c|c|c|}
\hline تدريسي في كلية التربية الرياضية /جامعة الموصل & بايوميكانيك & | - أ.د. وديع ياسين التكريتي \\
\hline تدريسي في كلية التربية الرياضية /جامعة الموصل & بايوميكانيك & 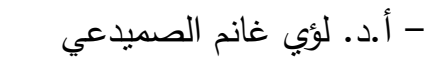 \\
\hline تدريسي في كلية التربية الرياضية/جامعة الموص & اختبارات (قياسر & - أ.م.د.عبدالكريم قاسم الجوادي \\
\hline تدريسي في كلية التربية الرياضية /جامعة الموصل & 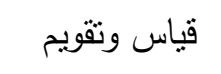 & ل م.د. هاشم احمد سليمان \\
\hline تدريسي في كلية التربية الرياضية /جامعة الموصل & 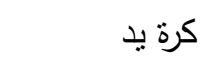 & د. كنعان محمود \\
\hline تدريسي في كلية التربية الرياضية /جامعة الموصل & 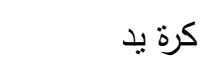 & أ.م.د. نوفل محمد محمود \\
\hline تدريسي في كلية التربية الرياضية /جامعة الموصل & 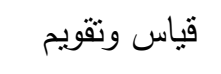 & ·م.د. ثيلام يونس علاوي \\
\hline تدريسي في كلية التربية الرياضية /جامعة الموصل & 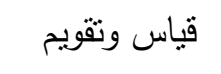 & 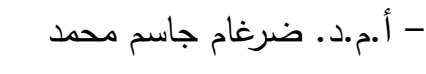 \\
\hline 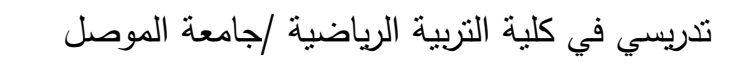 & قياس وتقويم & • م.د. سبهان محمود الزهيري \\
\hline 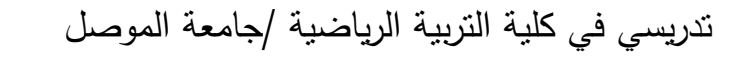 & 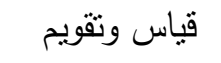 & •د. محي محم \\
\hline
\end{tabular}




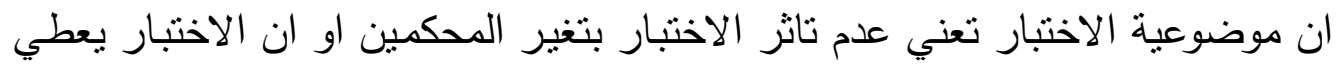

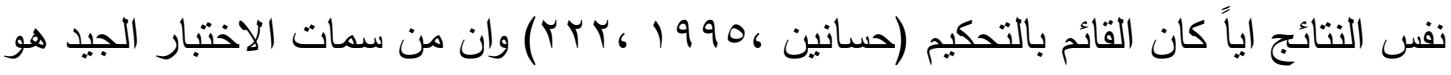
الدرجة العالية من الموضوعية وان درجة الموضوعية ستكون عالية اذا اعتمد الممتحن على اداة

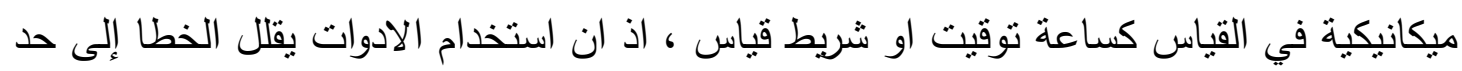

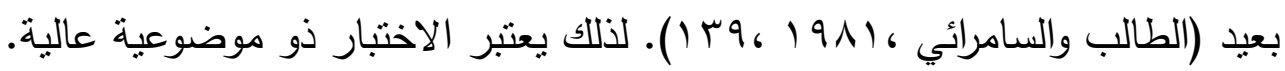

بـ اختيار متغير ات البحث: :

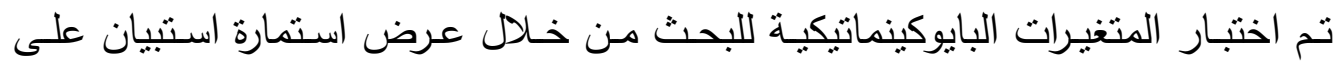

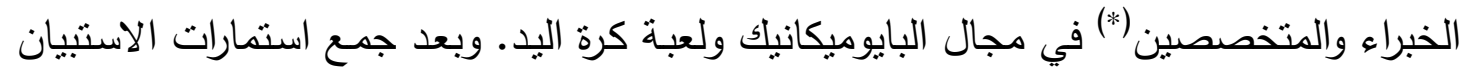
تم التوصل إلى الصيغة النهائية للمتغيرات الكينماتيكية للبحث.

ب-7 التجربة الاستطلاعية :

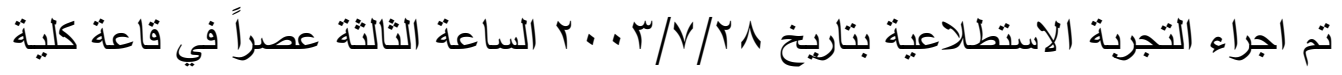

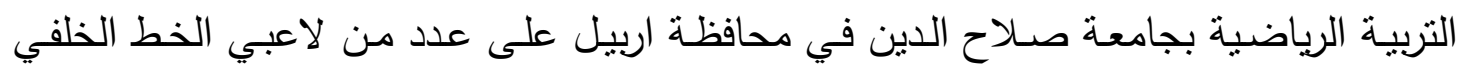

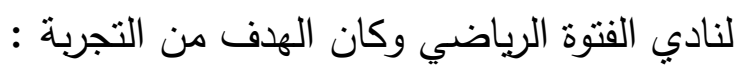
- التأكد من سلامة عمل الأجهزة. - تثبيث بعد وارتفاع الة التصوير عن التهرة، التلاعبين.

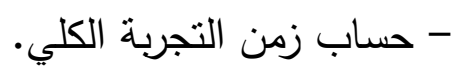

تدريسي في كلية التربية الرياضية /جامعة الموصل تدريسي في كلية التربية الرياضية /جامعة الموصل

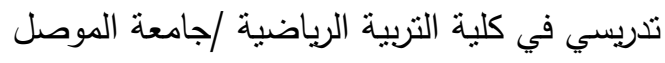

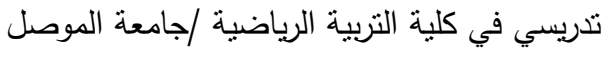
تدريسي في كلية التزبية الرياضية /لجامعة بغاداد-الجادرية تدريسي في كلية التربية الرياضية /جامعة بغداد الرية التربية

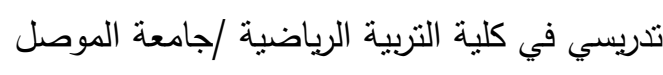

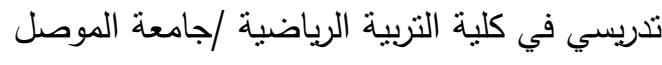

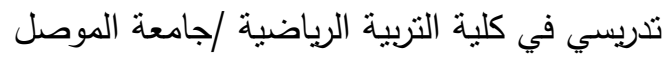

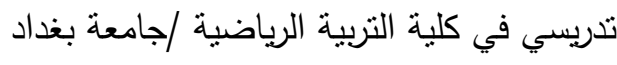
تدريسي في كلية التربية الرياضية /جامعة الموصل

\begin{tabular}{|c|c|}
\hline بايوميكانيك & - أ.د. وديع ياسين التكريتي \\
\hline بايوميكانيك & أ.د. لؤي غانم الصميدعي \\
\hline بايوميكانيك & أ.د. عارف محسن حساوي \\
\hline اختبارات (قياس وتقويم) & - أ.م.د. .عبدالكريم قاسم الجوادي \\
\hline بايوميكانيك & - أ.م.د. صريح عبدالكريم \\
\hline كرة يد & - أ.م.د. احمد مسالمة \\
\hline بايوميكانيك & أ.م.د. سعد نافع \\
\hline كرة يد & أ.م.د. كنعان محمود \\
\hline كرة يد & أ.م.د. نوفل محمد محمود \\
\hline بايوميكانيك & م.د. ايمان شاكر \\
\hline بايوميكانيك & م.د. ليث اسماعيل \\
\hline
\end{tabular}


- التعرف على عدد وكفاءة فريق الععل.

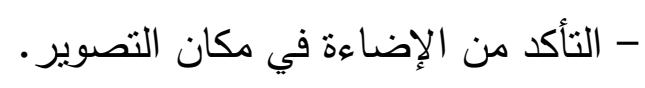
- التعرف على المشاكل المحتمل حدوثها في أثناء تتفيذ التجربة.

V- التجربة التهائية:

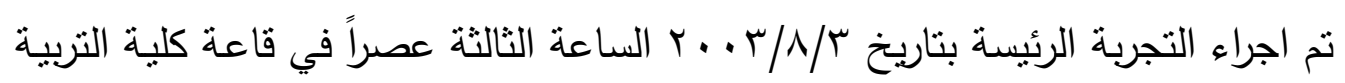
الرياضية بجامعة صلاح الدين في محافظة اربيل.

س-V-V- ا طريقة أجر اء التجربة:

تم اجراء تجربة البحث على العينة بالطريقة آلاتية: - أدى كل لاعب من عينة البحث الاختبار على ثنلاث مرات.

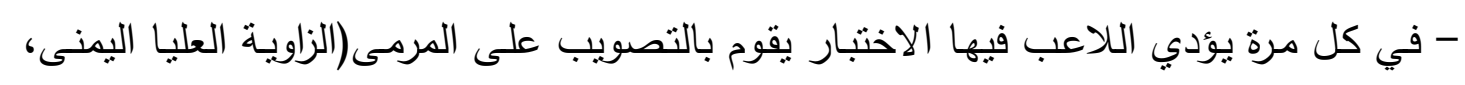
الزاوية العليا اليسرى ، الزاوية السفلى اليسرى ، الزاوية السفلى اليمنى) على الترتيب.

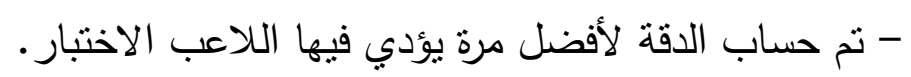

م- م طريقة استخلاص البيانات:

بعد ان تم تسجيل محاولات اللاعبين بوساطة التي تصوير فديوية نوع(Sony Digital)

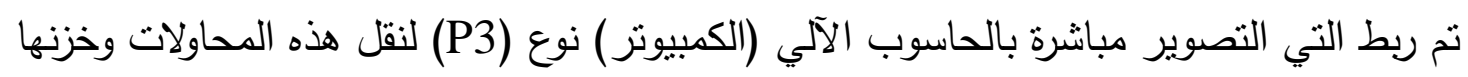

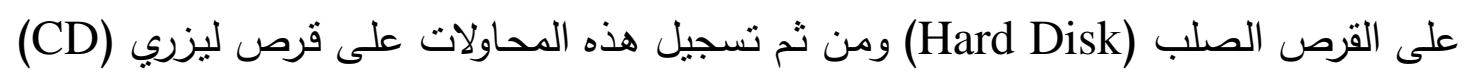

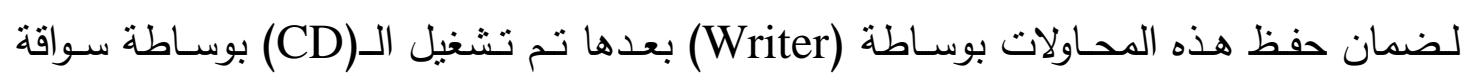
الأقراص (CD-Drive) الموجودة في جهاز الحاسـوب الآلكي وتم استخدام برنـامج (Wing)

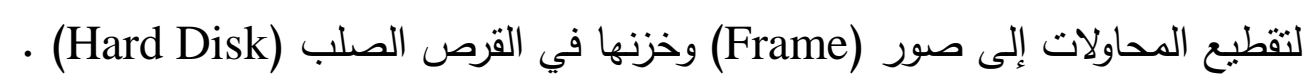

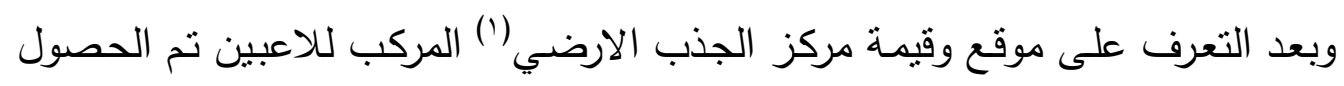

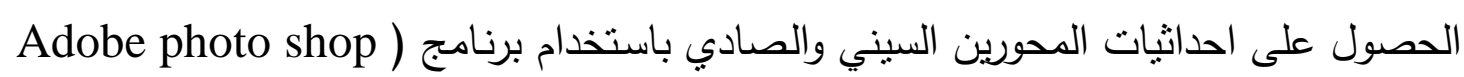
4) وحسب احداثيات الحاسبة النقطية ،حسب نقاط الثاثة (Pixel).ومن بعد تحديد الإحداثيات تم ادخال هذه البيانات في برنامج (Excel 97) وذللك لغرض تحويل هذه البيانات إلى قيم

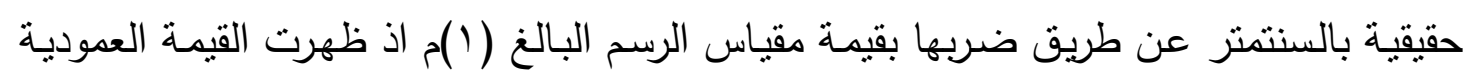

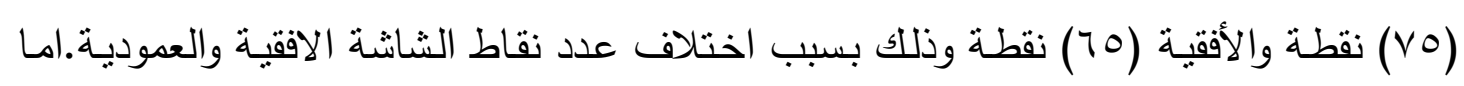

(1) تم استخراج مركز الجذب الأرضي المركب عن طريق الحاسوب بواسطة برنامج خاص مصمم من قبل

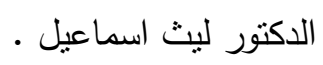


المقياس الخاص بالة التصوير الثانية والخاص بمتغيرات الكرة فقد ظهرت قيمة مقياس الرسم

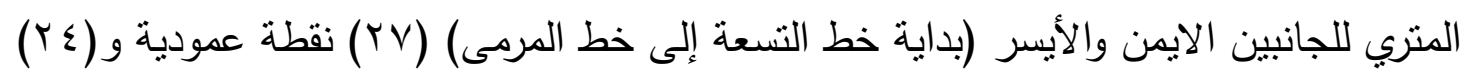
نقطة أفقية ومقياس الرسم الوسطي المتري (Y) نقطة عمودية و (Y) نقطة أفقية. وتم التعرف على قيم زوايا الذراعين للاعبين من خلال استخدام برنامج (Autocad)

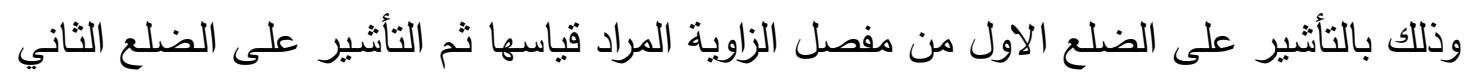
من زاوية المفصل فنظهر بصورة مباشرة قيمة هذه الزاوية.

ب-9 المعالجات الإحصائية: تم معالجـة البيانـات إحصائيا باستخدام برنـامج (Spss) اذ تم مـن خلالهه حساب قيم معامل الارتباط البسيط لبيرسون.

ع - عرض النتائج ومناقشتها فيما يأتي عرض لما نوصل الينه ومنان البحث من نتائج مع مناقشتها: ع - ا عرض ومناقثة نتائج الخطوة الاخيرة من الاقتر اب لعينة البحث. لتئ. (r) الجدول

يبين طول وزمن وسرعة الخطوة الأخيرة وأوساطها الحسابية وإنحرافاتها المعيارية

\begin{tabular}{|c|c|c|c|c|c|c|c|}
\hline الانحراف & الحسابي & الخامس & الرابع & الثالث & الثانب & اللاعب & $\begin{array}{l}\text { البحثغ عينة } \\
\text { البثرات }\end{array}$ \\
\hline $7,1 \leq$ & $9 \varepsilon, 1$ & $9 \leq$ & $1 \ldots$ & 90 & $1 \ldots$ & 10 & طول \\
\hline$\cdot, \cdot \leq \leqslant$ & דזא, & • & A & $\cdot, \varepsilon .0$ & $\cdot, \Gamma 00$ & $\cdot, \curlyvee \wedge \wedge$ & زمن الخطوة \\
\hline$r,, \leq 0$ & $r \wedge \varepsilon, V_{0}$ & $r q \wedge, \Sigma)$ & MI $\leqslant, \leqslant T$ & $T r \leqslant, 0 T$ & $r \wedge 1,79$ & $r 90,1 r$ & سرعة \\
\hline
\end{tabular}

يتبين من الجدول (r) ان هنالك اختلاف في طول خطوة الاقتراب الاخيرة لدى عينة

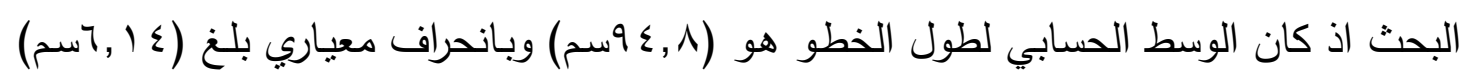


وكذللك في زمـن الخطوة للدى افراد عينـة البحـث اذ كان الوسط الحسابي لزمن الخطوة هو

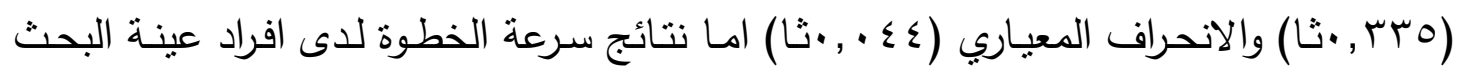

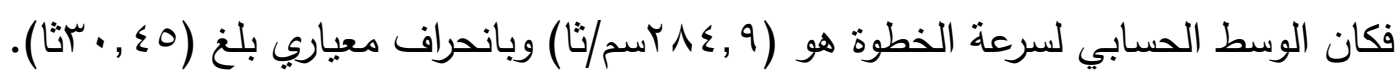

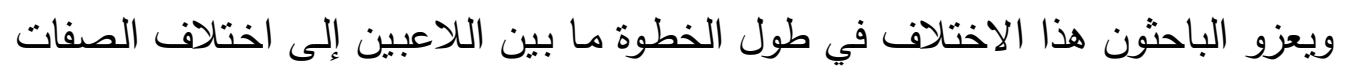

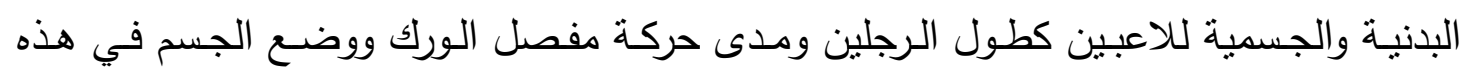

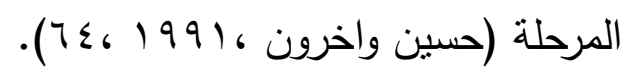

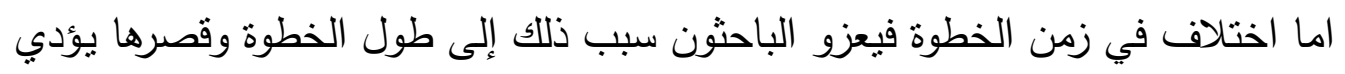

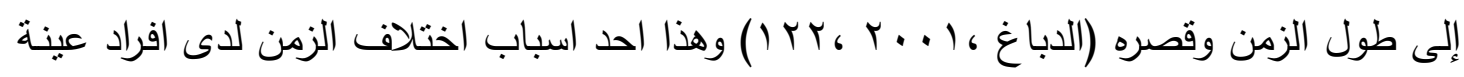
البحث.

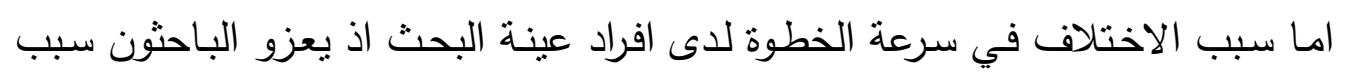

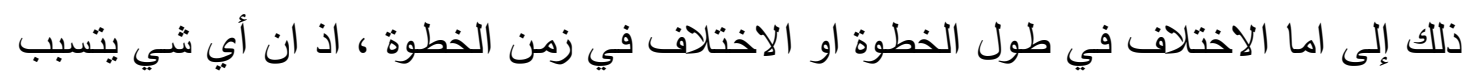
في اختلاف طول الخطوة سوف يؤدي إلى تقليل او زيادة السرعة. (Jacopy\& Fraly,1995,44)

كذلك يؤكد (حسين واخرون) يمكن زيادة السرعة عن طريق زيادة طول الخطوة مع ثبات الزمن والعكس صحيح وهذا ما حدث لاى افراد عينة البحث.

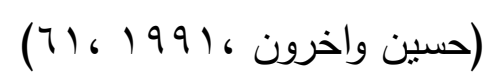

ومن اجل التعرف على العلاقة بين طول وزمن وسرعة الخطوة لدى عينة البحث ودقة التصويب

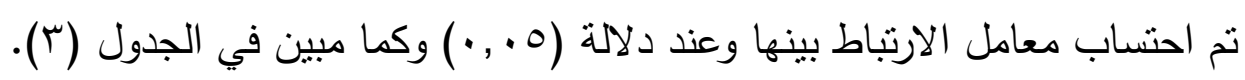

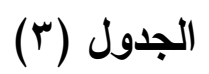

يبين معامل الارتباط بين طول وزمن وسرعة الخطوة

\begin{tabular}{|c|c|c|c|c|}
\hline دقة الخطوة & سرعة الخطوة & زمن الخطوة & طول الغطوة & المتغيرات \\
\hline & & & $1, \cdots$ & طول الخطوة \\
\hline & & $1, \cdots$ & $\begin{array}{l}\cdot, \leqslant 00 \\
\cdot, \leq \leqslant 1\end{array}$ & زمن الخطوة \\
\hline & $1, \cdots$ & $\begin{array}{l}\cdot, \wedge \vee q- \\
\cdot, .0 .\end{array}$ & $\begin{array}{l}\cdot, \cdot r_{1} \\
\cdot, \Lambda \cdot 0\end{array}$ & سرعة الخطوة \\
\hline $1, \ldots$ & $\begin{array}{l}\cdot, 107 \\
\cdot, 1.0\end{array}$ & $\begin{array}{l}\cdot, r \leq \\
\cdot, 979\end{array}$ & $\begin{array}{l}\cdot, K Y V \\
\cdot, O V I\end{array}$ & دقة التصويب \\
\hline
\end{tabular}

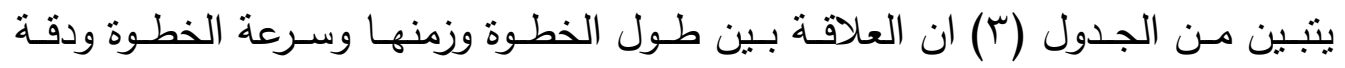

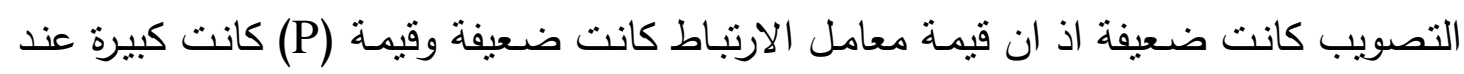


مستوى الدلالة. اما العلاقة بين زمن الخطوة وسرعتها فقد كانت علاقة عكسية وقوية اذ كانت

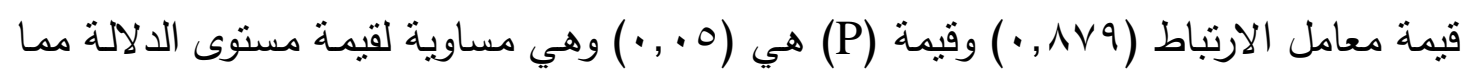

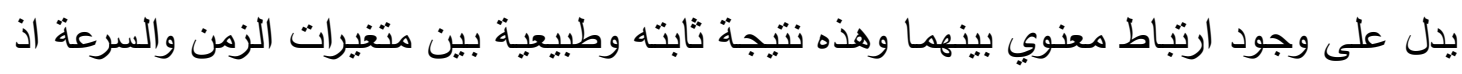
انه كلما قل الزمن زادت السرعة عند ثنات المسافة وحسب القانون الفيزيائي.

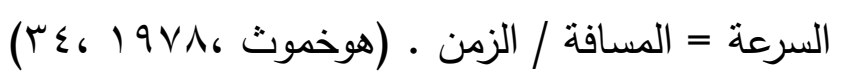

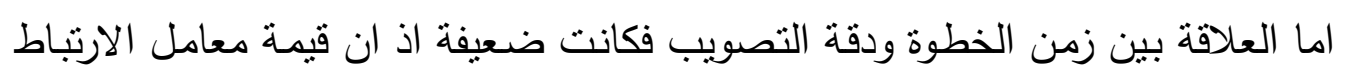

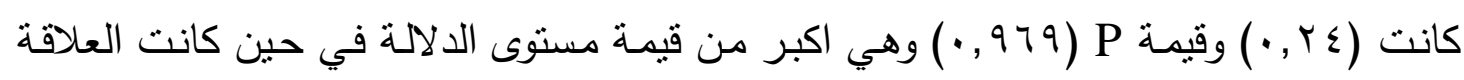

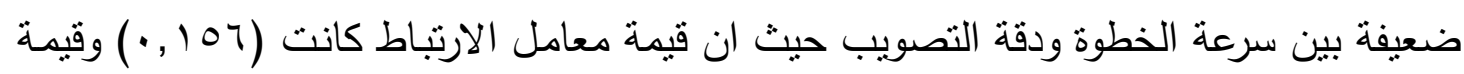
$\cdot(\cdot, \wedge \cdot 0) \mathrm{P}$ 
ع - ع عرض ومناقشة نتائج بعض المتغير ات البايوميكانيكية لاى عينة البحث

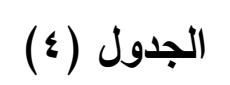

يبين قيم بعض المتغيرات الكينمايتيكية لحركة التصويب واساطها الحسابية وإحرافاتها المعيارية

\begin{tabular}{|c|c|c|c|c|c|c|c|c|c|}
\hline ألوصول إلى ألى ارتفاع & العمافة & المسافة & ارتقاع م ث ج & زاوية الطيران & زاوية الجذع & رجل الارية ورتكاز درجة & زاوية المرفق & زاوية الكتف & المتغيرات \\
\hline$\cdot, r \leq \tau \leq$ & $0 ., T V$ & A & 107 & rT,人т & $1 \cdot 1, \mathrm{~V}$ & $I T V, r T$ & $119, \leqslant Y$ & $97, Y)-$ & الاول \\
\hline - ro9r & דr & $V r, \wedge O$ & $17 \varepsilon$ & $19,0$. & $\Lambda T, \Sigma$. & $1 \leq 0,11$ & 97,90 & $1.9,99-$ & الثاني \\
\hline אדצץ,. & r), r $\varepsilon$ & ro, זᄉ & $177,7 \mathrm{~V}$ & $r \cdot, \varepsilon r$ & $\Lambda V, \cdot r$ & $100,0 \pi$ & $9 \leq, 97$ & qV, А५- & الثالث \\
\hline •, YVYT & rА, TV & $71,0 \leqslant$ & $17 \varepsilon$ & $r \cdot, l$. & 91,174 & $|r v, N|$ & $7 V, \leq q$ & $V \varepsilon, Y I-$ & الرابع \\
\hline$\cdot, r T \leq V$ & rA & $0 \wedge, \leq\rceil$ & $1 \leq \varepsilon$ & Mr, $\Sigma$. & $\Lambda), V$. & $I V \cdot, \varepsilon r$ & $101, \cdot 1$ & $1 \cdot r, I V$ & الخامس \\
\hline$\cdot, r \leqslant \vee \wedge$ & דצ,qu & $O \Lambda, \leqslant T Y$ & $101,94 \varepsilon$ & $r V, Y O \Lambda$ & $\Lambda \Lambda, q Y r$ & $1 \leqslant q, Y Y T$ & 1.V, & $97, \cdot 1-$ & س- \\
\hline$\cdot, \cdot 1 \wedge \vee$ & س1, & $1 \leq, 1 \leq 0$ & $9, Y \circ V$ & $0, r q r$ & $\Lambda, Y Y Y$ & 17,90 & س & IT, & $\varepsilon \pm$ \\
\hline
\end{tabular}

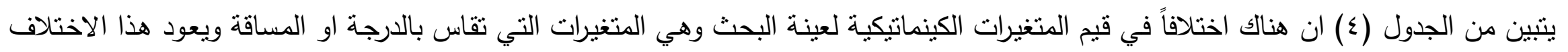

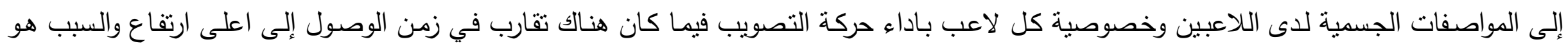
الاختلاف في سرعة اداء الحركة من قبل عينة البحث وهذا ما تتطلبه حركة التصويب من القفز عالياً ، ومن اجل التعرف على على العلاقة بين المتغيرات الكينماتيكية تم حساب معامل الارتباط بينهما والجدول (0) يبين ذللك. 
الجدول (•)

يبين قيم علاقة الارتباط بين المتغيرات الكينمايتيكية ودقة التصويب

\begin{tabular}{|c|c|c|c|c|c|c|c|c|c|c|}
\hline التصويب & الوصول إلى أعلى ارتفاع & العمودية & الأفقية & ارتفاع م ث & الطيران & الجذع & وربك رجل & الايمن & الايمن & اللاعب المتغيرات \\
\hline & & & & & & & & & $\begin{array}{l}.074- \\
.0 Y T r\end{array}$ & المرفق الايمن \\
\hline & & & & & & & & $\begin{array}{l}\qquad \leqslant V T \\
. . \sum Y T\end{array}$ & $\begin{array}{l}\because 171- \\
.1997\end{array}$ & ورك رجل الارتكاز \\
\hline & & & & & & & $\begin{array}{l}\because V Y \mu \\
\therefore 174\end{array}$ & 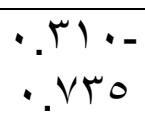 & $\begin{array}{l}\therefore \leqslant 0 Y \\
\therefore \leqslant \leqslant \varepsilon\end{array}$ & الجذع \\
\hline & & & & & & $\begin{array}{l}\because 101- \\
.1 .\end{array}$ & $\begin{array}{l}\because 191 \\
\therefore \text {. }\end{array}$ & $\begin{array}{l}\cdot Y \cdot r \\
\cdot V \leq \varepsilon\end{array}$ & $\begin{array}{l}. \leqslant 7 \leqslant \\
\therefore \leqslant T 1\end{array}$ & الطيران \\
\hline & & & & & $\begin{array}{l}\ddots r r r \\
.01 .\end{array}$ & $\begin{array}{l}\because|Y| \\
\because \wedge \leq T\end{array}$ & $\begin{array}{l}\because \varepsilon \cdot 9- \\
\because \leq 9 \leq\end{array}$ & $\begin{array}{l}-^{*} \\
\because q 1 r \\
\because \cdot r .\end{array}$ & $\begin{array}{l}. r r 9 \\
.799\end{array}$ & ارتفاع مث ج \\
\hline & & & & $\begin{array}{l}\because \text { UNA- } \\
. \text { VTr }\end{array}$ & $\begin{array}{l}\because .70 \leqslant- \\
. \quad \mathrm{TH}\end{array}$ & $\begin{array}{l}\because .90 \\
\therefore 979\end{array}$ & $\begin{array}{l}\because \cdot V Y \\
\because 9.9\end{array}$ & $\begin{array}{l}\because .41 \\
\because 971\end{array}$ & $\begin{array}{l}\because \mid \leqslant 1- \\
. \wedge r \mid\end{array}$ & الافقية \\
\hline & & & $\begin{array}{l}.701 \\
. Y Y V\end{array}$ & $\begin{array}{l}\because .0 V_{-} \\
\because 9 Y \wedge\end{array}$ & $\begin{array}{l}\theta 0 \leqslant 1- \\
. r \leqslant 7\end{array}$ & $\begin{array}{l}.1741 \\
\therefore 179\end{array}$ & 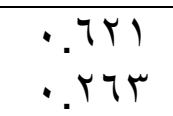 & $\begin{array}{l}\because 1 \cdot Y_{-} \\
\because \wedge Y 1\end{array}$ & $\begin{array}{l}\qquad Y Y I \\
\qquad Y Y I\end{array}$ & العمودية \\
\hline & & $\begin{array}{l}\because \leqslant V V \\
\therefore \leqslant 17\end{array}$ & $\begin{array}{l}\because \leqslant \Lambda . \\
\therefore \leqslant ा \psi\end{array}$ & $\begin{array}{l}. . T r V \\
. T \leq V\end{array}$ & $\begin{array}{l}\because \varepsilon 17- \\
\therefore \varepsilon \wedge V\end{array}$ & $\begin{array}{l}\cdot . r V \cdot \\
. T T 1\end{array}$ & $\begin{array}{l}\because .4 \% 9- \\
.0 \times 4\end{array}$ & $\begin{array}{l}\because \wedge \leqslant \wedge- \\
\because \vee \vee .\end{array}$ & $\begin{array}{l}.0 \leqslant \varepsilon \\
. r \leqslant \leqslant\end{array}$ & الوصول إلى أعلى \\
\hline & $\begin{array}{l}\because \text { Y人 } \\
. .7 \leqslant 1\end{array}$ & $\begin{array}{l}. Y \leqslant 1- \\
.797\end{array}$ & $\begin{array}{l}.291 \\
. r 90\end{array}$ & $\begin{array}{l}\because \varepsilon N V_{-} \\
\therefore \varepsilon \cdot 7\end{array}$ & $\begin{array}{l}\text { UYY- } \\
\therefore . Y Y .\end{array}$ & 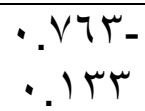 & $\begin{array}{l}\text { OYTY- } \\
\text { OTV. }\end{array}$ & $\begin{array}{l}.0 \leqslant \leqslant \\
. T \leq \leqslant\end{array}$ & $\begin{array}{l}\because . T \wedge \varepsilon- \\
\because . Y \cdot T\end{array}$ & التصويب \\
\hline
\end{tabular}

* يشير الرقم الاول الى قيم (ر) المحتسبة والرقم الثاني الى مستوى الدلالة 
يتبين من الجدول (0) وجود علاقة ارتباط معنوية بين ارتفاع مركز نقل الجسم وزاوية

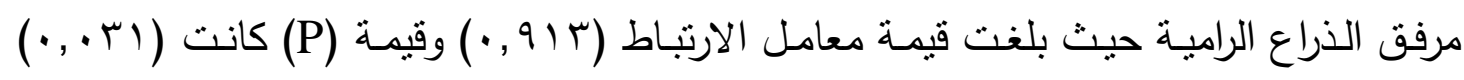
وهي اصغر من قيمة مستوى الدلالة (0. . ·) ويرجع سبب هذه العلاقة إلى عندما يرتفع مركز الارثة

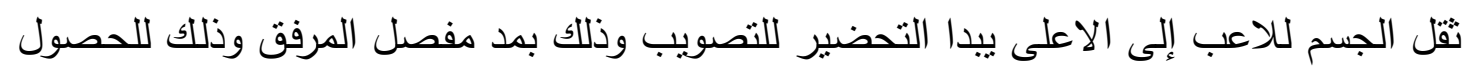

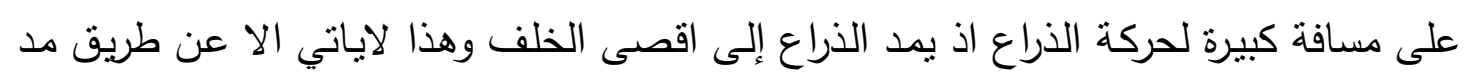

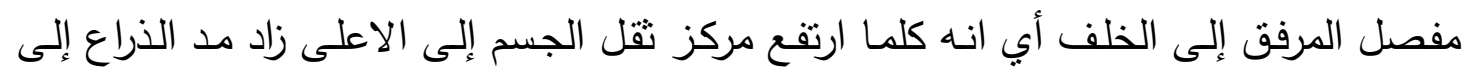

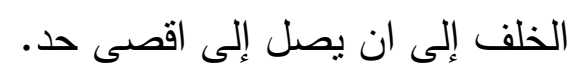
اما بقية العلاقات فكانت ضعيفة وهذا يعكس عدم النوافق والتتاسق بين اجزاء الجسم اثتاء التصويب وهذا ما ادى إلى ضعف التصويب عند اللاعبين.

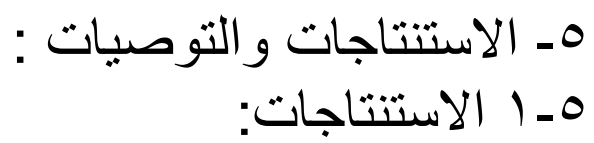

في ضوء النتائج المستحصلة عن طريق تحليل البيانات وفي ضوء الحقائق تبين ما يأني: ا ـ وجود اختلاف في قيم بعض المتغيرات البايوميكانيكية للأداء الحركي لمهارة التصويب من

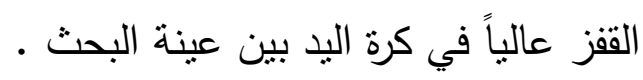
r. تؤثر الزيادة في زمن خطوة الاقتراب الأخيرة سلبياً على سرعة الخطوة ومن ثم تؤثر على لئ لئ سرعة حركة الرمي. r. العلاقة بين المتغيرات البايوكينماتيكية كانت أكثرها ضعيفة مما بعكس ضعف الدهاء اللاعبين.

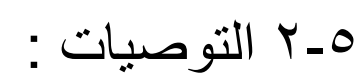
في ضوء الاستتناجات يوصي الباحثون بماياتي:

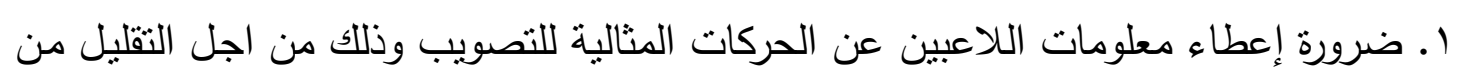
الأخطاء وبذللك تعمل على تقريب وتثابه الأداء.

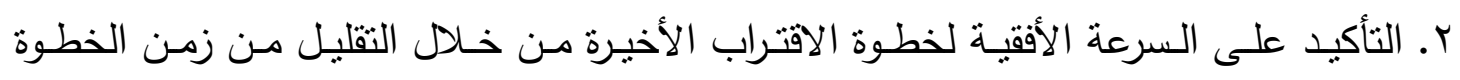

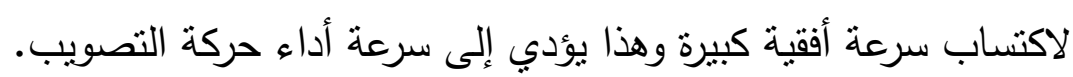

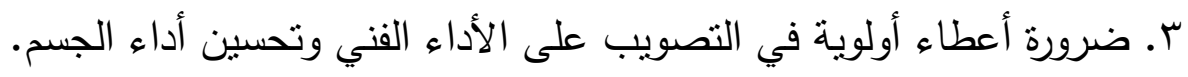




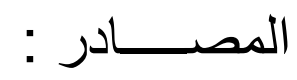

ا ـ اسـاعيل ، سعد محسن (799 (19) : تأثير أسـاليب تدريبية لتنميـة القوة الانفجاريـة للرجلين والذراعين في دقة التصويب البعيد بالققز عالياً في كرة اليد أطروحة دكتوراه- غير منشورة

كلية التربية الرياضية ،جامعة بغداد.

r. تركي ، علي وايمان شاكر (997 (1) :دراسة بعض المتغيرات البايوكينماتيكية لخطوة الارتقاء

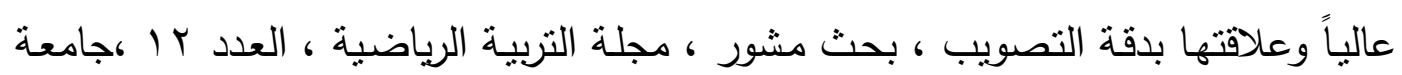
الموصل.

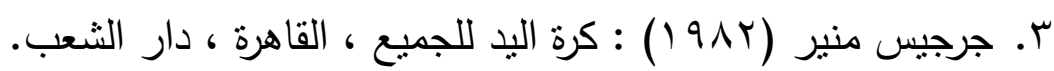
ع. حسام الدين ، طلحة (س99 (1) : الميكانيكا الحيوية الاسس النظرية والتطبيقية ، القاهرة ، دار الفكر العربي.

ه. حسانين ، محمد صبحي (9V9 ( ) : القياس والتقويم في التربية البدنية والرياضية ،دار الفكر

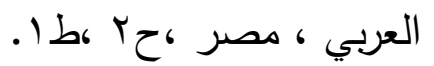

7 . حسانين محمد صبحي (990 (1) : القياس والتقويم في التربية البدنية والرياضية دار الفكر

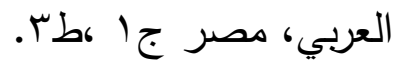

V. حسن،قاسم واخـرون (1991 ) : تحليـل الميكانيكيـة الحيويـة في فعاليـات العـاب الساحة

والميدان ،دار الحكمة ، البصرة.

^. حمـاد ، مفتي ابراهيم (991 (1) : التدريب الرياضي الحديث تخطيط وتطبيق وقيادة ، دار الفكر العربي، القاهرة. - مان.

9 ـ الخفاجي ، طالب ناهي (ع^9 (1) : فيزياء الرياضة البدنية دار الحرية للطباعة ، بغداد. • ا. الدباغ ، موفق سعيد (1 . . r) : دراسة عدد من المتغيرات الوظيفية والبايوميكانيكية في عدو • . . (م ، اطروحة دكتوراه غير منشورة ، كلية التربية الرياضية،جامعة الموصل. ا ـ شتاين ، هـانز جيرت وادجار فيدرهوف ( ع 9 ( ) : كرة اليد ترجمـة كمال عبدالحميد ، دار

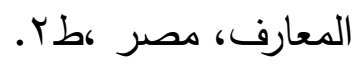

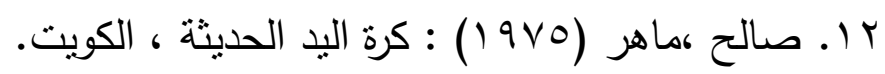

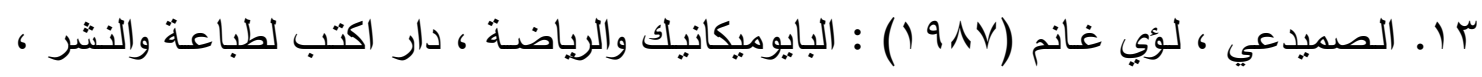
جامعة الموصل. ع ا. ـ عبدالبصير ، عادل (9 9 1 ) :الميكانيكا الحيوية ، التكامل بين النظرية والتطبيق في المجال الرياضي ، مركز الكتاب للنشر ، القاهرة ،ط ب.

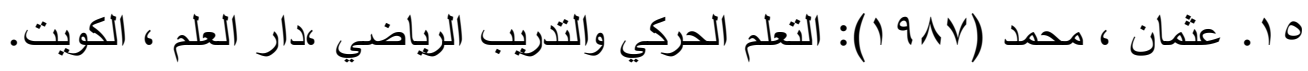


17 . . عـلاء الدين ، جمال (ـ99 (1): دراسـات معملية في بايوميكانيكا الحركـة الرياضية ، دار المعارف ، القاهرة ،طب.

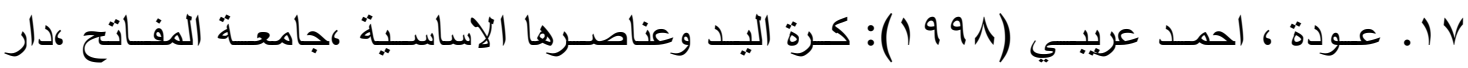
المطبوعات والنشر •

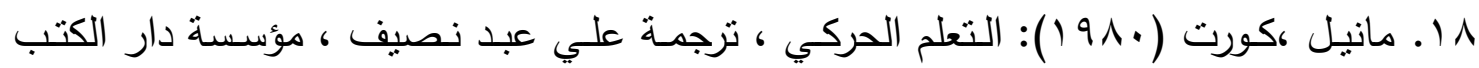
للطباعة والنشر ، الموصل.

9 1 ـ دحجوب وجيه ( •99 ()): التحليل الحركي الفيزياوي والفسلجي للحركات الرياضية مطابع التعليم العالي،بغداد.

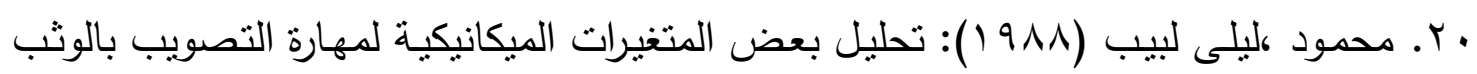
عاليا ، مجلد نظريات العدد الرابع /جامعة القاهرةً.

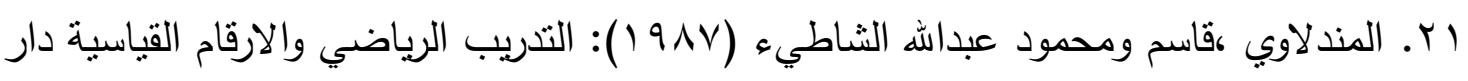
الكتب للطباعة والنشر . r r. موسى، عالية حسن واخرون (919 (1)): الفيزياء لطلبة علوم الحياة ، مطابع التعليم العالي، بغداد.

r r. الهلالي ،صادق (YVY (1)): فسلجة الجهاز العصبي ،مطبعة الادبي ، بغداد.

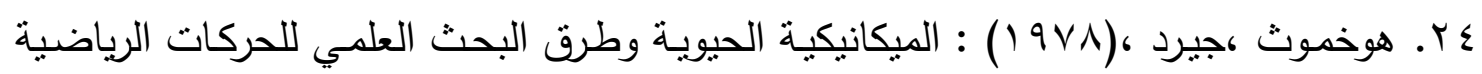

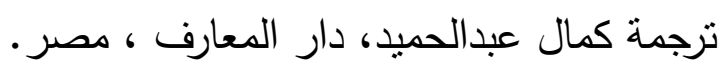

25. Facoby,Edand Fralay ,bod (1995): complete book of jump,printed in U.S.A. 